\title{
"O COMBATENTE MELHOR ALIMENTADO DA EUROPA": A ALIMENTAÇÃO DA FORÇA EXPEDICIONÁRIA BRASILEIRA E A ALIANÇA BRASIL-EUA DURANTE A SEGUNDA GUERRA MUNDIAL (1943-1945)
}

\section{"THE BEST FED FIGHTER IN EUROPE": THE FEEDING OF THE BRAZILIAN EXPEDITIONARY FORCE AND THE BRAZIL-US ALLIANCE DURING WORLD WAR II (1943- 1945)}

Dennison de Oliveira*

Resumo: Este texto se dedica a história da alimentação da Força Expedicionária Brasileira durante a Campanha da Itália na Segunda Guerra Mundial. São examinados tópicos como as negociações militares entre autoridades estadunidenses e brasileiras sobre o fornecimento de comida à FEB; as implicações do abastecimento de gêneros alimentícios de origem estadunidense e brasileira; a reação dos militares brasileiros aos alimentos que lhe foram fornecidos além mar; e a dieta mista adotada na prática pelas autoridades militares brasileiras. A pesquisa foi extensivamente baseada em memórias e relatos de veteranos de guerra, bem como a consulta a acervos documentais nacionais estrangeiros até aqui inéditos. .

Palavras-chave: História da Alimentação; Aliança Militar Brasil-EUA; Segunda Guerra Mundial.

\footnotetext{
* Universidade Federal do Paraná, Curitiba, Paraná, Brasil. E-mail: kursk@matrix.com.br
} 


\begin{abstract}
This text is about the history of feeding of the Brazilian Expeditionary Force during the Italian Campaign in World War II. Are discussed topics such as the military talks between US and Brazilian authorities on the provision of food to the FEB; the implications of the supply of food from US and Brazilian sources; the reaction of the Brazilian military to food provided to them overseas; and the mixed diet adopted in practice by the Brazilian military authorities. The research was extensively based on memories and reports of war veterans, as well unpublished national and foreign documentary collections.
\end{abstract}

Keywords: Food History; Military Alliance Brazil-US; Second World War.

Pensar os laços entre acervos e investigação histórica é refletir sobre o próprio métier dos historiadores.

\title{
Introdução: a alimentação de tropas brasileiras em combate no estrangeiro como problema de pesquisa
}

Os estudos dedicados ao tema da participação do Brasil na Segunda Guerra Mundial tem se expandido bastante em tempos recentes. A frequência com que o tema vem sendo discutido em congressos, simpósios, livros e artigos só tem aumentado e é de se prever que novas e substanciais descobertas e avanços ocorram num futuro próximo. Neste debate, o tópico relativo às relações Brasil-EUA, é um dos que mais tem atraído a atenção dos pesquisadores, além de se constituir já há algum tempo num tema clássico nessa área de estudos. ${ }^{1}$

Este artigo se dedica ao exame de um determinado aspecto da aliança militar firmada entre Brasil e Estados Unidos da América durante a Segunda Guerra Mundial, no caso, o fornecimento de comida às tropas da Força Expedicionária Brasileira que combateram na Campanha da Itália (1944-45). Trata-se de tema de grande importância uma vez que, no exame das questões afetas à produção, transporte, preparo e financiamento da aquisição de gêneros, é possível perceber toda uma série de conflitos, disputas e contradições entre as autoridades militares de ambos países bem como entre si próprias e com seus comandados.

A composição da dieta a ser oferecida aos soldados podia ter sido de origem totalmente estadunidense, totalmente brasileira ou uma combinação de ambos, como de fato veio a ocorrer. No processo de definição da origem da comida a ser servida às tropas entravam diversas variáveis relevantes. Dentre estas cabe destacar a necessidade, suposta ou real, de adequar qualquer nova dieta ao paladar dos militares brasileiros; o financiamento da aquisição dos gêneros, se seria feito através do pagamento à vista ou por meio do Lend Lease; $\mathrm{e}$, as atitudes e iniciativas de comando e tropa em serviço no estrangeiro diante da forma como era exercida, na prática, este aspecto particular da aliança militar com as forças armadas dos EUA. 
Desta forma, o estudo da alimentação oferecida aos membros da FEB durante a Campanha da Itália, acaba por se constituir numa útil estratégia de abordagem de uma série de questões afetas à História das Relações Militares Internacionais, bem como à História Cultural. No que se refere à História das Relações Militares Internacionais este objeto permite entender as diferentes concepções das autoridades de ambos os países sobre a forma pela qual deveriam serem alimentados em campanha os membros da FEB e o correspondente papel que as forças armadas de cada nação deveriam desempenhar neste processo. $\mathrm{O}$ tema é também de interesse da História Cultural porque se refere à História da Alimentação, abrangendo tanto os processos industriais da produção e preparo dos alimentos, quanto dos hábitos culturais ligados ao consumo de alimentos, incluindo ai o importante tema das transferências culturais manifestas nestas práticas, para não mencionar a "americanização" do Exército Brasileiro àquela época.

No que se refere especificamente à alimentação da FEB é de se notar, em que pese a importância do tema, a quase total ausência de quaisquer estudos a respeito. A exceção até aqui é o trabalho de Luciano Meron intitulado "Saco vazio não para em pé: a alimentação e os hábitos alimentares na FEB (19441945)"'2. Nesta comunicação de pesquisa o autor sintetiza os conflitos culturais decorrentes da mudança de dieta, de brasileira para estadunidense, ainda que servida com alguns ingredientes brasileiros; a diferenças nos quesitos de higiene e limpeza no preparo de alimentos nas unidades militares no Brasil em contraste com as práticas adotadas no IV Corpo de Exército dos EUA ao qual estava subordinada a FEB; e, a relação afetiva dos combatentes brasileiros com a comida do Brasil e aquela que conseguiam tanto obter como doar a civis italianos. No todo, trata-se de um texto que coloca a maior parte das questões fundamentais relativas à História da Alimentação da FEB, ao mesmo tempo em que sugere fontes, memórias e obras de referencia úteis para o entendimento da questão.

Este texto pretende aprofundar e problematizar ainda mais as questões levantadas por Meron, através do apelo a uma variedade de fontes oriundas de arquivos nacionais e estrangeiros, pretendendo se constituir uma contribuição tanto para o estudo da história da aliança militar Brasil-EUA quanto do processo de "americanização" pela qual passaram os membros da FEB que, certamente, também é um tópico importante da História do Brasil na Segunda Guerra Mundial.

\section{A Aliança Brasil-EUA e a questão da alimentação da Força Expedicionária Brasileira em combate na Itália}

Os eventos que culminaram com a formação da aliança Brasil-EUA na Segunda Guerra Mundial, bem como os desdobramentos daí decorrentes 
foram abordados em diversas obras, algumas tornadas clássicas nos estudos de relações internacionais. ${ }^{3}$ Já há algum tempo tomamos como tema de pesquisa a aliança militar firmada entre Brasil e Estados Unidos da América durante a Segunda Guerra Mundial, tendo como objeto as comissões militares conjuntas Brasil-EUA. Para planejar e executar as extensas e complexas operações militares abrangidas pelo texto do acordo firmado por ambos os países em 23.05.1942 foram criadas duas comissões conjuntas: a Joint Brazil United States Defense Commission - JBUSDC (Comissão Conjunta de Defesa Brasil Estados Unidos - CCDBEU) com sede em Washington (EUA) e a Joint Brazil United States Military Commission - JBUSMC (Comissão Militar Conjunta Brasil Estados Unidos - CMCBEU) com sede no Rio de Janeiro (RJ). Essas entidades compostas por militares de ambos os países serão referidas aqui por suas siglas originais em inglês, ou então através da menção à sua cidade-sede: a comissão em Washington e a comissão no Rio de Janeiro. Na citação dos textos se conservou a terminologia da época na qual os estadunidenses eram referidos e se referiam a si mesmos como "americanos". ${ }^{4}$

Das duas comissões a menos conhecida do público e dos pesquisadores é, certamente, a do Rio de Janeiro. A comissão em Washington, por sua vez, desde sempre despertou o interesse dos historiadores, já que em seu interior foram debatidas questões de grande importância para as atividades das forças armadas de ambos os países aliados, tais como o planejamento da defesa da região nordeste do Brasil, a criação e organização da Força Expedicionária Brasileira, etc. $\mathrm{O}$ fato do titular brasileiro da comissão, o General Estevão Leitão de Carvalho, ser conhecido como um militar de grande reputação e renomado escritor, foi um fator importante a interessar os historiadores pela JBUSDC. Seu livro autobiográfico, no qual relata o papel que desempenhou na comissão de Washington, se tornou referência obrigatória para todos estudiosos do assunto, atingindo também um grande número de interessados, em especial aquela parte do público consumidor de obras da história da participação do Brasil na Segunda Guerra Mundial. Contudo, mesmo assim a maior parte das iniciativas tomadas pela JBUSDC seguiu desconhecida dos pesquisadores até bem recentemente. ${ }^{5}$

Porém, ainda mais desconhecida é a comissão do Rio. A JBUSMC permaneceu numa espécie de limbo, raramente sendo citada ou levada em conta pelos pesquisadores interessados no tema. $\mathrm{O}$ fato não deixa de ser intrigante, uma vez que coube a ambas comissões, e não apenas à de Washington, o exercício de uma série de atividades da mais alta relevância para a história da aliança militar Brasil-EUA na Segunda Guerra Mundial. Dentre estas, cabe destacar a questão da alimentação que seria servida aos membros da Força Expedicionária Brasileira (FEB) em operações de combate além mar, no período compreendido entre junho de 1944, quando se deu a chegada dos primeiros efetivos militares brasileiros à frente italiana, até maio de 1945, quando se 
encerram as hostilidades no teatro de operações europeu. ${ }^{6}$

O exame das negociações relativas à forma pela qual seriam alimentados os militares brasileiros em combate na Itália é muito importante porque revela as diferentes percepções, iniciativas e projetos das partes envolvidas com relação a forma pela qual deveria ser entendida e conduzida a aliança militar então vigente. Como notado, também é uma fonte útil de informações sobre os hábitos alimentares dos militares brasileiros e as implicações do processo de transição para a dieta de origem estadunidense.

De saída é importante notar que o tópico relativo à alimentação jamais foi formalizado por qualquer das partes envolvidas. A questão da alimentação das tropas brasileiras, da mesma forma que vários outros itens de fundamental importância para as operações conjuntas de combate na frente de batalha como, por exemplo, prisioneiros de guerra e aplicação da justiça militar, nunca foram formalizadas em qualquer documento escrito que tenha sido efetivamente firmado entre as autoridades militares estadunidenses e brasileiras. $\mathrm{O}$ fato tem a ver, por um lado, com o caráter conflituoso da relação entre o Ministro da Guerra Brasileiro, o General Eurico Gaspar Dutra, e o representante do governo brasileiro na JBUSDC, General Estevão Leitão de Carvalho. E, por outro, com a expectativa de Dutra em obter das autoridades estadunidenses, termos ainda melhores para as aquisições de bens e serviços que pretendia efetuar naquele país, procrastinando a formalização dos necessários acordos adicionais.

Examinando a sequência de eventos na história da aliança militar BrasilEUA durante a Segunda Guerra Mundial fica claro o elevado grau de conflito entre os gestores brasileiros foi, sem dúvida, uma das causas que levou a um grande número de tratativas a ficar sem ser formalizada ou tornada oficial. Antes de seguir para os EUA para assumir seu cargo na JBUSDC, Leitão de Carvalho não teve instruções e nem credenciais da parte de Dutra, embora tenha recebido várias determinações de Góes Monteiro. As determinações do Chefe do Estado-Maior eram extensas e diziam respeito a uma variedade de missões de informação e planejamento que, para serem todas cumpridas, exigiriam uma grande e variada equipe de assessores e consultores militares. Mas Leitão de Carvalho inicialmente seguiu sozinho, devendo se juntar em Washington ao representante da FAB e da Marinha de Guerra do Brasil para compor a parte brasileira da comissão. Para agravar, não foram fornecidos a Leitão de Carvalho os códigos para transmissão de mensagens do Exército Brasileiro, apenas os do Itamaraty. ${ }^{7}$

Uma vez reunida a Comissão em Washington já em sua primeira sessão plenária, em 03.09.1942, emitiu nada menos de cinco resoluções. Nova reunião, no dia 11 de setembro, aprovou mais duas resoluções de números 6 e 7. No dia 3 de outubro, outras três resoluções, de números 8,9 e 10 foram aprovadas. A resolução número 11 foi aprovada a 13 de novembro de 1942. Não foi possível determinar quando teriam sido aprovadas as resoluções de números 12 e 13. A 
resolução 14 foi aprovada em 20.01.1943. A data de aprovação da resolução número 15 ocorreu em 12 de abril. A recomendação 16 foi aprovada em 21 de agosto. Finalmente, deveria ter existido uma resolução 17, mas ela jamais foi aprovada. Justamente essa última resolução é que deveria regular as relações da FEB com comando do Exército dos EUA em operações além mar, incluindo as vitais questões relativas à alimentação, prisioneiros de guerra e justiça militar.

Os membros da Comissão de Washington viajaram ao Rio de Janeiro em maio de 1943. Um dos objetivos da viagem era prover uma reunião preparatória àquela que iria formalizar a participação de tropas brasileiras na luta contra $o$ Eixo além mar, a ser realizada posteriormente em Washington. Esta foi uma das poucas oportunidades em que o General Leitão de Carvalho encontrou com Dutra para trocar ideias e definir linhas de ação. Em comum acordo eles resolveram apoiar uma proposta preliminar elaborada pela Comissão de Washington que previa:

O transporte da tropa para o teatro de operações ficaria a cargo dos americanos; suprimentos e aprovisionamentos, em material e víveres, igualmente a cargo deles, com exceção dos uniformes, roupa interna, placas de identificação e tudo o mais quanto o Brasil pudesse fornecer, segundo propusera o presidente da Comissão de Washington. ${ }^{8}$

Até então a expectativa era que os estadunidenses proveriam toda alimentação demandada pela FEB. Essa decisão foi alterada em julho de 1943. Naquela época o General Leitão de Carvalho escreveu a Dutra sistematizando o que já havia sido discutido no interior da Comissão em Washington com as autoridades militares dos EUA.

... transporte de tropa para a zona das operações, a cargo dos órgãos americanos competentes; suprimentos e aprovisionamentos - materiais e víveres - igualmente a cargo dos ditos órgãos, com exceção de uniformes, roupa branca, placas de identificação, calçado e determinados gêneros alimentícios, bem como tudo quanto o Brasil pudesse fornecer. ${ }^{9}$

Esta foi a primeira vez que se manifestou a intenção do governo brasileiro de prover parte da alimentação da FEB. Tais fornecimentos eram entendidos como necessários à etapa de adaptação dos pracinhas ao paladar da dieta estadunidense que, ao fim do processo, seria a única a ser servida à tropa brasileira.

Em agosto de 1943, Dutra viajou aos EUA para participar das discussões 
que culminariam com a realização da sessão plenária da JBUSDC do dia 15 daquele mês, que promulgaria a recomendação 16 , oficialmente intitulada "Colaboração do Exército Brasileiro e da Força Aérea Brasileira com o Exército Norte Americano em Teatros de Operações fora do Continente". O texto da resolução fixava a composição de um Corpo Expedicionário composto por três divisões de infantaria e elementos de apoio, entre os quais uma unidade aérea, que seriam organizados de acordo com as tabelas vigentes no Exército dos EUA. Essas tropas ficariam subordinadas ao comando e direção estratégica do exército estadunidense, que se encarregaria de manter as suas linhas de comunicação e abastecimento. Todo material seria fornecido pelos EUA, com exceção do equipamento individual, placas de identificação e do fardamento, os quais seriam de origem brasileira.

A visita de Dutra aos EUA nada fez para melhorar as relações entre o Ministro da Guerra e o chefe brasileiro da JBUSDC. Dutra se esforçou ao máximo em ignorar Leitão de Carvalho e mantê-lo à margem tanto da conversa privada que tivera com Marshall na ocasião, quanto das tratativas feitas diretamente com o chefe estadunidense da JBUSMC em seu retorno ao Rio, na época, o General Hobbs. A partir daí, Dutra passou a ignorar os contatos e comunicações que Leitão de Carvalho se esforçava em lhe enviar. A relação de Góes com Leitão de Carvalho foi igualmente ruim. ${ }^{10}$

A etapa final da organização da FEB seria a aprovação da recomendação 17 que detalharia a forma pela qual se relacionaria o Corpo Expedicionário brasileiro com as forças armadas estadunidenses. Dentre as questões pendentes se encontrava o uso do Lend Lease para pagar pelas despesas do Corpo Expedicionário no exterior; o retorno da tropa no fim da guerra ao Brasil levando suas armas; do uso da força aérea expedicionária em apoio às tropas brasileiras; da possibilidade do desmembramento do Corpo em efetivos menores sob comando estadunidense para atender a situações táticas determinadas; do abastecimento de gêneros alimentícios de origem brasileira (feijão, arroz, carne-seca, mate, etc.) até que a tropa se acostumasse às rações dos EUA, etc. Outras questões igualmente pendentes diziam respeito a itens como comando, justiça, pagamentos, prisioneiros e material de guerra capturado. Em 18 de outubro de 1943 Leitão de carvalho escreveu a Dutra um resumo do que se pretendia com a Resolução 17. Nele constava que os artigos de subsistência da FEB seriam fornecidos pelo Exército dos EUA, a conta do Lend Lease. ${ }^{11}$ Dutra não retornou qualquer comunicação ao General Estevão Leitão de Carvalho a respeito durante um bom tempo.

O silêncio de Dutra em relação às comunicações de Leitão de Carvalho só foi quebrado mais de um mês depois. No final de novembro de 1943, Dutra fez saber a Leitão de Carvalho que considerava prematuras tanto a recomendação 16 quanto a 17. Dizia ele que estava em andamento um estudo que levaria a assinatura de um novo acordo militar com os EUA, especificamente dedicado 
ao financiamento através do Lend Lease para o emprego da FEB. A esse respeito Leitão de Carvalho pouco ou nada podia fazer. Afinal de contas, com o retorno de Dutra ao Brasil em setembro de 1943, a participação do representante do Exército Brasileiro na JBUSDC foi relegada à quase total irrelevância. Informalmente, perdeu Leitão de Carvalho suas prerrogativas de representante do governo e negociador da política militar brasileira perante as autoridades militares estadunidenses, em proveito de papéis puramente secundários, como o acompanhamento dos feridos da FEB em tratamento em hospitais dos EUA, dos militares brasileiros que frequentavam cursos em academias militares estadunidenses e alguns outros poucos assuntos de menor relevância.

Revelador da marginalização de Leitão de Carvalho das tratativas feitas diretamente por Dutra com os membros estadunidense da Comissão do Rio foi a carta que Dutra lhe enviou pedindo que fosse garantido pelas autoridades militares dos EUA o envio de alguns gêneros alimentícios do Brasil para a FEB quando estivesse em serviço na linha de frente além mar. No que se refere a esta carta de Dutra a Leitão de 13 de novembro de 1943 o destinatário assim comenta sobre as demandas do Ministro da Guerra no Rio de Janeiro:

Com grande espanto nosso, voltou ele a tratar de um assunto que considerávamos de todo esgotado: o suprimento de alguns gêneros alimentícios da culinária reúna para o rancho da tropa no estrangeiro. Parecia-nos, com efeito, perfeitamente satisfatórios os dados que a respeito lhe havíamos fornecido e, no entanto, começava sua carta insistindo sobre informações mais completas sobre as facilidades que seriam concedidas à remessa dos gêneros para a tropa... no sentido de ser facilitado o transporte de alguns gêneros peculiares à nossa gente (feijão, arroz, carne-seca), e que reputa indispensável à tropa em seu período inicial de adaptação... estávamos todos de acordo quanto à conveniência de se proporcionar aos nossos soldados, no teatro de guerra, essa pequena satisfação, que relembrava a pátria distante. Mas o que se podia fazer, estava feito, prometendo o Estado Maior americano tudo empenhar para que fossem as rações adaptadas aos hábitos brasileiros... por detrás do chefe da delegação brasileira, se estariam realizando entendimentos, entre o representante do Estado-Maior americano (na comissão do Rio) e o Ministro da Guerra Brasileiro, acerca de assunto de nossa alçada, enfraquecendo-se, assim, a autoridade da representação militar de nosso país, com sacrifício dos interesses nacionais... ${ }^{12}$ 
Ficou, assim, deixado em aberto uma decisão definitiva sobre a alimentação da FEB. De forma provisória e informal se seguiu a orientação de que os brasileiros além-mar seriam alimentados pela logística do Exército dos EUA, sendo prevista uma complementação de gêneros alimentícios de origem brasileira, no que se pretendia ser uma etapa de transição até que a tropa se acostumasse a consumir exclusivamente rações alimentícias de origem estadunidense. $^{13}$

As unidades que comporiam a primeira das três divisões de infantaria do futuro Corpo Expedicionário Brasileiro começaram a se reunir no Rio de Janeiro em março de 1944. Os preparativos para envio além-mar dos primeiros efetivos de combate brasileiros entravam em sua reta final. Naquela época Dutra negociava diretamente com o representante estadunidense na JBUSMC as diversas questões pendentes sobre a FEB, incluindo alimentação. Em Washington Leitão de Carvalho só chegou a tomar conhecimento destes fatos através das autoridades militares dos EUA na JBUSDC, neste caso, o General Ord. Em suas memórias ele se refere ao:

...memorando dirigido, em 14 de março (de 1944), pelo Coronel Hobbs ao Estado Maior do Exército do seu país. Informando-o sobre a conversação que tivera com o general Anor Teixeira dos Santos, chefe do estado maior do Corpo Expedicionário Brasileiro, em organização, e entregue ao chefe da nossa Delegação pelo General Ord. No encontro, que se realizara a 11 do referido mês, declarara-lhe o general brasileiro estar concluído o trabalho a seu cargo; e que, antes de apresenta-lo ao Ministro da Guerra, gostaria de examina-lo conjuntamente com ele. Esse trabalho compreendia planos relativos à organização da força expedicionária, que deveriam ser submetidos ao Ministro: ... gêneros alimentícios e outros artigos a transportar com as ditas unidades... gêneros alimentícios exclusivamente brasileiros...14

O que teria sido tratado pelo representante de Dutra com o representante do Exército dos EUA na Comissão do Rio no que diz respeito à alimentação da FEB? A esse respeito é instrutivo examinar o documento citado, no caso, o memorando trocado entre estas duas altas autoridades militares:

Memorando 14/03/1944

Tema: Força Expedicionária Brasileira 
.... é interessante notar que o Departamento de Guerra brasileiro está considerando levar um suprimento de seis meses de arroz, feijão, mandioca, mate em folha, mate em pó, cigarros e fósforos brasileiros, com o escalão inicial, e eles esperam aumentar gradualmente o total de comida americana a ser servida as unidades brasileiras e diminuir o total de comida brasileira, e isso será tudo que teremos de levar com cada escalão. Baseado em um efetivo de 20.000 homens, um suprimento de seis meses destes itens chegará a 2.500 toneladas... ${ }^{15}$

Foi desta forma que o General Leitão de Carvalho ficou sabendo das intenções de Dutra com relação à alimentação da FEB. Haveria um prolongado período de adaptação com uma dieta mista, até que a tropa se acostumasse com as rações estadunidenses. Na prática, como se viu, a quantidade de comida brasileira entregue à FEB na Itália foi tão grande que durante praticamente toda guerra foi possível oferecer uma dieta mista. É altamente provável que todos cinco navios transporte de tropas que levaram os efetivos da FEB à Itália entre junho de 1944 e janeiro de 1945 contivessem em seus porões enorme tonelagem de gêneros alimentícios destinados à alimentação da tropa na Itália.

O último capítulo relativo à história das negociações sobre a alimentação da FEB entre as altas autoridades brasileiras e estadunidenses transcorreu quando o primeiro escalão das tropas brasileiras já se encontrava em território italiano, com seus efetivos ocupados com os preparativos para entrada em ação de combate. Foi nesse contexto que o Ministro da Fazenda de Vargas foi aos EUA com uma incumbência que, no entender de Leitão de Carvalho, já se encontrava superada, qual seja, a forma pela qual a FEB seria suprida pelos EUA e como esses fornecimentos seriam pagos. O General brasileiro assim descreve esses fatos:

... em julho de 1944 o Ministro Souza Costa, de passagem em Washington, estava procurando resolver o caso do fornecimento de gêneros à $\mathrm{FEB}$, a respeito do qual trouxera uma nota, e pedia a minha colaboração. $\mathrm{O}$ documento trazido pelo Ministro da Fazenda era do teor seguinte: "quando se tratou da organização da Força Expedicionária, declarou o representante do Governo Americano que o Brasil, além do pagamento de vencimentos da sua tropa, só entraria mais com as fardas e o equipamento. Agora exige-se também o fornecimento de todos gêneros de alimentação para as nossas tropas, quer estejam reunidas em um único setor, quer divididas em vários, ou se permitirá abasteçamse elas nos depósitos e armazéns americanos, mediante pagamento à vista. A primeira hipótese importará na remessa 
contínua de gêneros alimentícios e na montagem de toda a aparelhagem necessária ao rancho, o que é muito difícil; a segunda aumentará a nossa despesa de uma importância não prevista". ${ }^{16}$

A importância do documento reside no fato de que revela, pela primeira vez, a intenção de se fornecer exclusivamente dieta de origem brasileira à FEB, supostamente uma opção imposta pelos membros estadunidenses na Comissão do Rio. Embora reconhecendo os problemas de ordem prática implícitos nesta opção, os custos eram colocados em confronto com outra opção, o pagamento à vista pelos gêneros de origem estadunidense. A informação era desconcertante porque, até então, prevalecia o acordo ainda não firmado em Washington segundo o qual todos gêneros alimentícios seriam fornecidos pelos EUA e seriam pagos pelo Lend Lease. A esse respeito Leitão de Carvalho fez saber ao Ministro da fazenda o que sabia sobre o assunto e, mais ainda, o quanto ignorava sobre as tratativas então em curso no Rio de Janeiro:

... o Projeto da Recomendação no. 17, enviado ao Ministro da Guerra em 29 de outubro de 1943. Com relação à alimentação da tropa, o que a Delegação americana propôs e a Delegação brasileira aceitou, foi o fornecimento da alimentação pelo Exército americano, para pagamento pelo Lend Lease... (sublinhado no original)... se o Ministro da Guerra do Brasil recusou aceitar o fornecimento para pagamento pelo Lend Lease - o que é possível, embora a delegação nada saiba - e se não aceita o fornecimento direto pelos órgãos de aprovisionamento do Brasil, nem concorda com a compra nos armazéns americanos para pagamento à vista; que solução poderá o Chefe da Delegação brasileira sugerir, se a autoridade americana não encontrar uma nova? ${ }^{17}$

$\mathrm{Na}$ ausência de qualquer orientação adicional da parte de Dutra só restou a Leitão de Carvalho concluir que seguia de pé o acordo inicialmente rascunhado, mas jamais formalizado, da resolução 17 . No que se referia ao tema da alimentação da FEB a proposta inicial estabelecia claramente que:

Quanto à questão do fornecimento de gêneros pelo Brasil, no período de transição entre a alimentação brasileira e a norte-americana, como fora sugerido pelas autoridades militares brasileiras, também continua de pé o que o General Ord declarou nas conversações do Rio de Janeiro, em maio de 1943, isto é, ser possível a remessa, dependendo apenas de praça nos navios de transporte das tropas. ${ }^{18}$ 
O que se pode concluir do exame da documentação relativa às negociações entre as altas autoridades militares brasileiras e estadunidenses é que, no que dizia respeito a alimentação da FEB, havia alguns consensos e muitas dúvidas. O principal consenso é que seria indispensável fornecer à tropa brasileira em operações além-mar diversos itens da culinária nacional. A partir daí surgiram as dúvidas, por exemplo, se tal complementação se daria: a) transitoriamente como etapa de adaptação em direção à uma dieta totalmente estadunidense, como era o entendimento dos membros brasileiros e estadunidenses da Comissão em Washington; b) permanentemente combinandose, no caso, uma oferta contínua de alimentos brasileiros e estadunidenses, como aparentemente Dutra pode ter desejado, face às questões práticas suscitadas pela adoção de uma dieta exclusivamente brasileira. Parece fora de dúvida que todos reconheciam a impraticabilidade de se embalar, despachar, preparar e oferecer aos combatentes da FEB na linha de frente uma dieta que fosse exclusivamente de origem brasileira.

\section{A alimentação dos combatentes brasileiros na Itália (1944-1945): algumas avaliações}

O entendimento da questão requer que se examine também o ponto de vista dos demais escalões militares, a começar pelos mais diretamente afetados pelas decisões tomadas nos altos centros decisórios em Washington e no Rio de Janeiro, isto é, a tropa engajada em operações de combate na frente italiana. Tal exame deve ser feito levando-se em conta o contraste entre a alimentação a que, desde sempre, estavam habituados nos quartéis brasileiros e aquela que, efetivamente, lhe foi servida na Itália.

Existem diversas menções a comida servida para a tropa na Itália em memórias, relatos e livros publicados pelos veteranos de guerra. Uma das obras mais sistemáticas a respeito é a coletânea "Depoimentos de Oficiais da Reserva sobre a FEB" publicada em 1950. Como o título da obra já indica, trata-se de uma coletânea de depoimentos de oficiais da reserva, todos vindos para a FEB diretamente da vida civil onde ou eram profissionais liberais ou estavam matriculados em cursos superiores destinados a estas carreiras. Uma vez que foram todos dispensados do Exército com a dissolução da FEB logo após o final da guerra, estavam quase que inteiramente livres para descrever da forma a mais crítica possível suas experiências como membros do Exército Brasileiro na Campanha da Itália. Nenhum deles seguia carreira militar e, portanto, não tinham a recear perseguições e represálias por parte das autoridades militares. $\mathrm{O}$ fato de terem vindo diretamente da vida civil para atuarem como oficiais também deve ser levado em conta, uma vez que isso os fazia ainda mais críticos das vicissitudes e restrições inerentes à vida como militar, à qual não estavam habituados. 
Assim, o sentido do livro acaba sendo extremamente crítico da condução da guerra por parte do governo e das autoridades militares, uma vez que são denunciados vários casos de omissão, irresponsabilidade, amadorismo, despreparo, autoritarismo, censura e até de racismo nas fases de preparação e mesmo durante as ações de combate da Força Expedicionária Brasileira. É compreensível que o Exército tenha se empenhado em recolher a obra, numa prática de censura direta, alegando ser ofensiva às forças armadas. Tudo isso faz do livro uma fonte valiosa e extremamente útil para se entender uma série de aspectos da participação do Brasil na Segunda Guerra Mundial.

No que diz respeito à comida vale a pena citar o depoimento de José Alfio Piason. Ele era $1^{\mathrm{o}}$ Tenente da Reserva e, quando convocado, chegou ao posto de subcomandante da $3^{\mathrm{a}}$ Companhia do $6^{\circ}$ Regimento de Infantaria. Ele também exerceu o cargo de oficial de informações (S2) do Estado-Maior do $1^{\circ}$ Batalhão do $6^{\circ}$ RI. Após a guerra se formou em medicina e seguiu carreira como médico. Ele descreve assim a dieta oferecida nos quartéis aos convocados para o serviço militar em tempo de guerra:

Durante o longo período de preparação para a guerra e até a partida da tropa para o estrangeiro, absolutamente deficiente, especialmente em sua qualidade, foi a alimentação a ela fornecida; já na época em que o $6^{\circ} \mathrm{RI}$ permanecia em sua sede (Caçapava e Taubaté), resumia-se o cardápio praticamente a café (sem leite), pão (sem manteiga), arroz, feijão e carne; vê-se por aí que o déficit em elementos essenciais era acentuadíssimo; isso, aliado à monotonia (dias, meses, anos, a mesma coisa), fazia que os "arranchados", por força dos regulamentos... mas tendo meios outros de manutenção... apesar de deverem comer no quartel... preferiam fazê-lo em pensões e bares... ${ }^{19}$

O hábito de se recusar a comida servida nos quartéis e se buscar alternativas fora parece ter sido amplamente disseminado, só não alcançando proporções maiores por conta das restrições impostas pelos custos. De fato, a maioria dos engajados jamais teve condição de arcar com as despesas de pagar, numa base diária, pelas suas refeições em bares, pensões e restaurantes próximos ao quartel.

A importância da reação à péssima comida servida nos quartéis pode ser melhor compreendida examinando os resultados obtidos numa pesquisa realizada pelo Major Médico da Reserva Mirandolino Caldas. Ele foi inicialmente lotado como neuropsiquiatra na Junta de Saúde encarregada de selecionar indivíduos para serviço na FEB. No decorrer da atividade de seleção médica ele compilou nada menos de nove diversas motivações para 
um sentimento generalizado entre os convocados que ele descreve como "As causas dos Desesperos e da Má Vontade" entre os que seriam enviados para travar a Segunda Guerra Mundial além mar. Em ordem de importância o ítem "Má alimentação nos quartéis" aparece já em segundo lugar nessa lista, só sendo suplantado por "Questões econômico-financeiras". ${ }^{20}$

As questões econômico-financeiras a que ele se refere dizem respeito às perdas materiais sofridas pelos convocados. Segundo ele, por conta da convocação, uns temiam perder o emprego, ou o salário, no caso, a metade dele que o empregador deveria seguir pagando aos seus funcionários recrutados para a FEB. Os recém-convocados reclamavam que essa redução salarial tornava impossível manter a família. A situação dos que trabalhavam por conta própria era ainda pior, uma vez que se viram obrigados a abandonar totalmente suas atividades comerciais ou de prestadores de serviço, com a correspondente perda destes ganhos. Como se vê, tratava-se de uma questão extremamente angustiante e que ameaçava a subsistência dos convocados e seus dependentes.

O segundo ítem em ordem de importância, em se tratando de entender as motivações da baixa moral dos convocados para o serviço militar em tempo de guerra, é justamente a má alimentação nos quartéis. É notável que a comida de qualidade sofrível não só impactasse a realidade presente dos convocados, como também prognosticasse para muitos um futuro sombrio. Tais sensações são descritas assim:

Muitos alegam que estão enfraquecendo e são obrigados a fazer refeições fora gastando o que não podem gastar, porque o ordenado não lhes dá para tanto. E ficam a meditar... "se, aqui, é assim, imaginem quando sairmos do Brasil". ${ }^{21}$

É compreensível, pois, que entre as sugestões que este médico neuropsiquiatra fez aos seus superiores, visando o levantamento moral da tropa conste expressamente, entre as medidas de caráter permanente, em primeiro lugar "nutrir bem, cientificamente, todos os soldados". Tal prioridade era assim justificada:

Um homem com fome, ou mal nutrido, é incapaz de qualquer esforço e se torna presa fácil das doenças, das emoções de medo e de todas as fraquezas. Não é exagero dizer que os comandantes de batalhões devem cuidar da boa alimentação dos seus soldados, como velam as mães carinhosas pela alimentação dos seus filhinhos. ${ }^{22}$

Tais recomendações não foram acatadas enquanto a tropa permaneceu no Brasil. Somente ao iniciarem a viagem além mar, quando passaram a serem 
alimentados pelos estadunidenses, é que finalmente melhorou a qualidade da comida que lhes era servida. Ao contrário das pessimistas expectativas de muitos, a comida servida à tropa não piorou com a saída do país. Pelo contrário, melhorou muito, embora não em todos aspectos. O impacto da passagem deste tipo de dieta para aquela usualmente servida aos combatentes pela logística estadunidense foi enorme. São comuns os depoimentos dos veteranos de guerra onde se salienta o choque experimentado pela oferta abundante, variada e higiênica de alimentos que eram o padrão das forças armadas dos EUA. Segundo Piason:

... passou-se ao regime balanceado e farto fornecido pelos americanos aos brasileiros, semelhante ao fornecido para suas próprias tropas; em contraste com o que se comia no Brasil, passou-se a ter realmente "breakfast", "dinner" e "supper", consistindo tudo em um copo de suco de frutas, café com leite, pão e manteiga em abundância, ovos com presunto, cereais e legumes em quantidade, carne e frutas em conserva das mais variadas espécies, doces, diariamente. Pode-se dizer, usando uma nossa frase muito expressiva, que o pracinha tirou então a "barriga da miséria". ${ }^{23}$

Provavelmente o tenente da reserva que escreveu mais extensivamente sobre o tema da alimentação da FEB foi Ubirajara Dolácio Mendes, autor do capítulo "Soldado com fome não briga", onde discorre sobre o contraste entre a alimentação habitualmente servida nos quartéis do Exército Brasileiro à época da Segunda Guerra Mundial, com aquela de origem estadunidense. Tratava-se de pessoa extremamente culta que, na vida civil, exerceu a profissão de advogado e foi, mais tarde, professor da Faculdade de Economia e Administração da USP e Diretor do Arquivo Público do Estado, dentre outras atividades. ${ }^{24}$ Ele descreve a comida normalmente servida nas unidades militares brasileiras da seguinte forma:

... o nosso soldado não estranha, e raro reclama, a alimentação que lhe dá o "rancho" das unidades militares, cujo cardápio é basicamente constituído por feijão, arroz e jabá (carne-seca). É até mais fácil ouvirem-se reclamações quando haja falta do feijão e do arroz, ainda mesmo quando esses dois pratos foram substituídos por outros mais substanciosos... O praça brasileiro, todavia, é geralmente de boa índole, muito tolerante e calmo. Em consequência, só protesta quando o feijão está muito bichado, ou o jabá excessivamente mal-cheiroso. ${ }^{25}$ 
Segundo ele o impacto inicial sobre o paladar causado pela passagem à dieta de origem estadunidense teria sido enorme, provavelmente aumentado por se tratar de refeições servidas no navio-transporte da Marinha de Guerra dos EUA. A bordo do navio de transporte de tropas superlotado com cerca seis mil homens só era possível servir duas refeições por dia. Correspondentemente, tais refeições teriam de ser ainda mais fartas, concentrando em duas porções o que usualmente seria servida em três. Segundo ele tais refeições teriam sido recebidas da seguinte maneira:

E o praça brasileiro arregalou os olhos, atônito, ao ver que serviam feijões brancos, macarrão, bifes, ovos fritos, maças ou peras, um pão branco, macio como pão de ló. O café era servido em canecões de porcelana e o leite, do tipo desidratado, distribuído pelas mesas, em latas, para que cada um se servisse à vontade. As sobremesas eram sempre variadas: frutas em calda, doces, sorvetes. ${ }^{26}$

Uma vez desembarcados em terra ao cabo de uma viagem de quinze dias teve início um regime misto de alimentação no qual a base eram os suprimentos fornecidos pelos estadunidenses, complementado por ingredientes da culinária brasileira, trazidos a bordo dos mesmos navios transporte de tropas. A adaptação dos cozinheiros aos ingredientes de origem estrangeira não foi nada fácil, tendo se verificado várias confusões. Passada uma difícil etapa inicial foram fornecidos aos brasileiros pelas autoridades militares estadunidenses na Itália vários cursos de cozinha e culinária, capacitando os cozinheiros da FEB a melhor manusearem os ingredientes vindos dos EUA. Paralelamente, muito experimentalismo e autodidatismo, na aprendizagem do manuseio destes alimentos, também ocorreu, como descreve Ubirajara:

Foi só com o tempo, pelo sistema de ensaio e erro, com muito boa vontade e o auxilio de intérpretes - que traduziam as receitas impressas nas latas e pacotes - que os pracinhas designados para o nosso rancho aprenderam a cozinhar. A alimentação, quantitativa e qualitativamente, passou a ser soberba. Numa só refeição tínhamos feijão branco com batatas, purée de batatas, fritadas de ovos com presunto, bolinhos de carne, vagens, pão branco acompanhado de uma geléia, creme de amendoim ou manteigas, sobremesa de frutas em calda, café com leite. E a variação era grande entre os pratos salgados: milho verde cozido, ervilhas, macarrão, ensopados de carne, beterrabas, nabos ou cenouras em pedaços, queijo amarelo, espinafre, etc. Uma vez ou outra, em vez de carne de vaca, recebíamos peru ou galinha. Grande parte desses alimentos vinha, geralmente, 
já preparada e em latas, bastando aquecer. As frutas em calda também variavam: maças, peras, abacaxis, pêssegos, damascos, ameixas, "cocktail" de frutas. Adicionados a isso tudo, vinham sempre sucos de laranja, abacaxi, "grape-fruit" ou tomate. Nunca pudemos tolerar esses dois últimos. (Num parêntese: depois de um ano deste regime, não é de admirar que os pracinhas, de volta ao Rio, tivessem assomos de revolta, quando lhes serviram, no rancho, o já conhecido feijão preto, bichado, arroz em papa e jabá com mau odor). ${ }^{27}$

Encerrando o exame das considerações que Ubirajara faz da alimentação servida à $\mathrm{FEB}$, cabe destacar a frequência com que era oferecida a comida de origem brasileira em proporção à estadunidense. Segundo ele, sempre existiu a dieta mista, combinando ingredientes estadunidenses e brasileiros, embora com tendência ao declínio da participação destes na medida em que prosseguia a guerra. É o que ele descreve nesta passagem:

Pois apesar de tal riqueza no cardápio, o soldado brasileiro sentia falta do feijão-com-arroz e farinha. E somos obrigados a admitir que, ao menos nisso, houve alguma previdência por parte dos organizadores da FEB: uma certa quantidade de feijão, arroz e farinha era distribuída às companhias para o rancho. Nos primeiros tempos, comíamos feijão-comarroz todos os dias. Com o tempo, porém e principalmente com a chegada sucessiva de outros escalões, parece que o suprimento foi se esgotando. De modo que, pelo fim da guerra, o prato brasileiro só era servido uma ou duas vezes por semana. ${ }^{28}$

O que se pode concluir destes depoimentos é que vigorou, ao longo da Campanha da Itália, o regime misto de alimentação, no qual predominavam ingredientes estadunidenses complementados por alguns itens da culinária brasileira. Jamais chegou a se concretizar, assim, a inicialmente pretendida "americanização" integral da dieta servida aos brasileiros em ação de combate no exterior. Contudo, a manutenção desse regime misto implicou diversos desafios aos encarregados de sua gestão e operação.

Cumpre, pois, examinar o ponto de vista dos encarregados de alimentar a tropa em ação na Itália, no caso, os membros do Serviço de Intendência (SI) da FEB. Cabia ao SI, dentre tantas outras atividades, transportar, estocar, distribuir e garantir condições de preparar os alimentos destinados à FEB. Do ponto de vista da organização destas atividades, assumia importância central a composição da dieta: seria estadunidense, brasileira ou uma combinação de ambas? A resolução das questões afetas à logística de embalagem, transporte, 
preparo e consumo de alimentos vindos dos EUA e/ou do Brasil tinham implicações distintas e, portanto, uma definição nesse sentido era essencial para o planejamento das atividades do SI no decorrer da Campanha da Itália. A composição da dieta também tinha que levar em conta, pelo menos em algum grau, as preferências do consumidor final. A esse respeito o Chefe do SI/FEB, Coronel Lavaquial Biosca, se manifestou em livro lançado em 1950:

É que sem contestar a excelência da ração americana, quer do ponto de vista higiênico, quer do ponto de vista do seu valor energético... fácil não foi, ainda assim, obter de imediato a sua aceitação a cem por cento pela tropa brasileira, devido a que, além do paladar completamente diferente ao que os nossos homens estavam habituados, quase nunca era satisfatória em volume, aspecto este que na alimentação brasileira chega a proporções exageradas. Afigurava-se que a ração americana era quantitativamente deficiente, motivo principal das reclamações registradas, criando sério problema de ordem não só alimentar como psicológica. ${ }^{29}$

É interessante examinar o ponto de vista do encarregado de gerir os serviços afetos à alimentação da tropa, em especial no que se refere ao regime efetivamente adotado (misto) em contraste com outros que se pretendia implantar, no caso, a dieta exclusivamente estadunidense ou exclusivamente brasileira. Segundo ele, a manutenção do regime misto teria sido um equívoco ou, na melhor das hipóteses, um meio termo que não deu certo.

O regime de alimentação mista, que só não vigorou na realidade durante a ofensiva (final), tinha impedido, de um lado que o homem se adaptasse definitivamente à alimentação americana única, sem, de outro, proporcionarlhe, em variedade e quantidade convenientes, a alimentação brasileira, gerando com isso o problema da continuidade, $\mathrm{e}$ demonstrando logo que não se deveria ter saído da seguinte alternativa: ou a alimentação americana, ou alimentação brasileira, de maneira única. ${ }^{30}$

À luz da experiência colhida com o assunto, o SI demandou à intendência do $\mathrm{V}$ Exército dos EUA diversas mudanças nos suprimentos então fornecidos à FEB. Foi pedido para se mudar ingredientes, excluir totalmente alguns e ampliar as quantidades de outros. Como foi notado, alguns itens da culinária estadunidense (como suco de tomate e suco de grapefruit) eram recusados porque tidos como intragáveis; outros, como no caso do arroz, a quantidade 
fornecida era tida como insuficiente. O resultado das demandas da Intendência brasileira junto as autoridade militares dos EUA na frente italiana foi o seguinte:

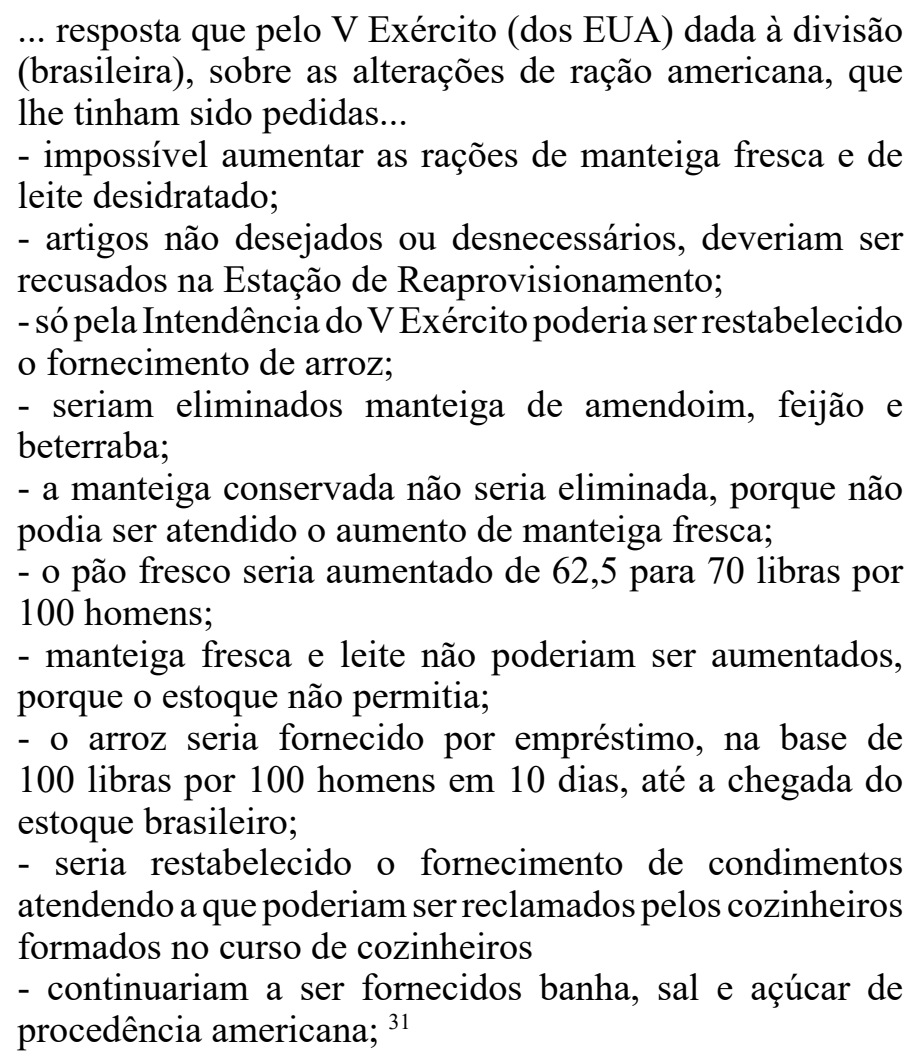

O comandante da intendência da FEB também fez notar aos seus superiores as implicações de se adotar uma dieta exclusivamente estadunidense ou brasileira. Na realidade havia várias razões de ordem prática na adoção de uma dieta exclusivamente estadunidense. Uma delas dizia respeito à disponibilidade de cozinheiros já formados, perfeitamente capazes, depois de um difícil período inicial, de adaptar os ingredientes e temperos fornecidos pelos estadunidenses ao gosto brasileiro.

Não obstante, o Coronel Biosca também fazia notar que era perfeitamente possível se adotar uma dieta exclusivamente brasileira. Nesse sentido, foram feitas sugestões quanto à melhor forma de selecionar, embalar e transportar os ingredientes de origem nacional até o front italiano, quando passaria, então, à responsabilidade do SI/FEB. O que deve ser destacado aqui é que nem remotamente o comandante da intendência da FEB pretendia reproduzir na Itália o limitado e medíocre padrão alimentar então vigente nos quartéis brasileiros. Muito pelo contrário, o que se pretendia para essa dieta composta exclusivamente por gêneros de origem nacional era que fosse, em boa medida, uma emulação do padrão estadunidense. Uma enorme variedade e diversidade de itens, em alguns casos equivalentes aos dos EUA, foi prevista para compor a 
ração de campanha do Exército Brasileiro em operações de guerra no exterior. Pra ele a embalagem dos produtos brasileiros demandados era inteiramente possível sendo sugeridas embalagens equivalentes as dos EUA para mais de 40 itens que deveriam vir do Brasil. ${ }^{32}$

A extensa e variada lista de ingredientes demandados para compor a dieta exclusivamente brasileira da FEB constituía, sem dúvida, um agudo contraste com o onipresente e invariante cardápio de feijão-arroz-jabá que seguia vigorando nos quartéis do Brasil porque incluía, dentre outros ítens: açúcar, café, mate, sal, banha, arroz, três tipos de feijão (preto, manteiga e mulatinho), seis tipos de farinha (mandioca, trigo, arroz, milho, maisena, aveia laminada), macarrão, bolachas, seis tipos de carne beneficiada (vaca, porco, galinha, carne em conserva, toucinho), peixe em conserva, ovos em pó, chocolate em pó, doces de frutas em calda e secas, marmelada, goiabada, bananada, sucos de frutas, leite condensado, manteiga com sal, óleo de salada, ervilhas, vários tipos de legumes desidratados (cebolas, batatas, etc.), massa de tomate, temperos e especiarias, sabão, papel higiênico, cigarros, fósforos, tabletes de chocolate, chicletes, artigos de higiene pessoal, etc. ${ }^{33}$

Outra contribuição do Coronel Biosca sobre a questão da dieta a ser adotada pela FEB foi a pesquisa realizada sobre os gostos alimentícios da tropa. Tal investigação ficou a cargo dos respectivos oficiais de logística (S-4) do Estado Maior de cada uma das unidades. As respostas colhidas nesta investigação se referiam apenas a duas opções, o regime misto e o exclusivamente brasileiro, não havendo menção à possível adoção de uma dieta composta apenas por ingredientes estadunidenses:

... podia já naquele momento a Intendência Divisionária informar que em visita feita aos S-4 das unidades da frente:

Opinaram pelo regime de alimentação exclusivamente brasileira: Esquadrão de Reconhecimento, Cia. de Transmissões, $1^{\circ}$ Batalhão de Saúde, $2^{\circ}$ Grupo de Artilharia, $4^{\circ}$ Grupo de Artilharia e $6^{\circ}$ Regimento de Infantaria;

Opinaram pelo regime de alimentação mista: $1^{\circ}$ Regimento de Infantaria, $11^{\circ}$ Regimento de Infantaria, $1^{\circ}$ Grupo de Artilharia, $3^{\circ}$ Grupo de Artilharia e $9^{\circ}$ Batalhão de Engenharia. ${ }^{34}$

Tais resultados de pesquisa, se é que são merecedores de crédito, parecem bastante inconclusivos. Grosso modo, metade das tropas pesquisadas afirmou preferir regime de alimentação exclusivamente brasileira e cerca de outra metade o misto. Embora o grau de exatidão dessa pesquisa possa ser 
objeto de debate, parece claro que não havia unanimidade entre os pracinhas sobre o regime de alimentação que deveria lhes ser oferecido. Na prática, vigorou o regime misto, frustrando um grande número de combatentes que afirmou preferir exclusivamente comida de origem nacional.

Das experiências de Dutra ao combatente melhor alimentado da Europa: as autoridades militares brasileiras e a questão das reações da tropa à dieta disponível

Conforme já observado, desde setembro de 1943 que Dutra passou a ignorar o representante brasileiro na Comissão em Washington, tratando dos preparativos para o embarque da FEB diretamente com o representante do Exército dos EUA na Comissão do Rio de Janeiro. Examinando a documentação legada pela JBUSMC no Rio é possível descobrir que Dutra havia decidido realizar algumas experiências com os membros da FEB, a fim de testar a possibilidade de servir à tropa além-mar exclusivamente a dieta de origem estadunidense.

Memorando para o Coronel Milton A. Hill, GSC. 25.02.1944. Tema: Resposta ao questionário preparado para sua viagem brasileira, remetido pelo Coronel R. H. Hobbs, GSC, Rio

Como você sabe, estamos planejando suprir a Força Expedicionária Brasileira com todos seus suprimentos, incluindo comida se possível. O Departamento de Guerra Brasileiro está agora estudando a possibilidade da FEB usar exclusivamente nossa ração. Neste sentido, os oficiais e convocados da FEB estão sendo alimentados com uma ração similar à nossa, vários dias por semana, como uma experiência. Se isso não funcionar será necessário suprir a FEB com arroz, feijão e carne-seca, preferivelmente de origem brasileira. Alguns suprimentos podem ser transportados se houverem porões disponíveis. ${ }^{35}$

Tal informação é inédita, uma vez que até aqui não se tinha conhecimento desta iniciativa do Ministério da Guerra: fazer uma experiência com alguns membros da FEB, então ainda em processo de concentração no Rio de Janeiro, para testar a viabilidade de se adotar exclusivamente rações dos EUA. Infelizmente não foi possível se obter mais informações a respeito, por exemplo, a origem das rações utilizadas na experiência tida como "similar" à dos EUA, mas não idêntica à esta ou mesmo de procedência propriamente estadunidense; o efetivo tomado como amostra, tanto em composição quanto em número total; e, os resultados ali colhidos.

Independentemente de quais tenham sido os resultados dessa experiência com seres humanos, o fato é que poucas semanas depois as autoridades militares 
dos EUA na Comissão do Rio já tinham sido colocadas a par da necessidade de se fazer embarcar, junto com o primeiro escalão de tropas brasileiras a serem enviadas para a Itália, uma substancial quantidade de gêneros alimentícios de origem brasileira. É o que se lê no documento datado de 14 março de 1944 já citado, onde consta que Dutra considerava levar com o primeiro escalão um suprimento de seis meses de arroz, feijão, farinha de mandioca, mate em folha, mate em pó, cigarros e fósforos brasileiros, enquanto seria gradualmente incrementado o total de comida dos EUA destinado a FEB. ${ }^{36}$

Alguns documentos oficiais contam uma versão muito mais coerente $\mathrm{e}$ menos sujeita ao empirismo de como transcorreu a definição da dieta da FEB. Em seu relatório à Vargas relativo as atividades do ano de 1944 Dutra descreve de que forma foi definida a alimentação que deveria ser destinada à FEB além mar. Segundo ele, inicialmente se pretendia que todos abastecimentos do tipo ficassem a cargo do Exército Brasileiro, o qual se encarregaria de viabilizar a oferta de uma dieta composta exclusivamente por gêneros nacionais. Contudo, inexistia uma definição oficial sobre qual deveria ser a composição desta dieta de ingredientes brasileiros, não sendo feita menção à proposta elabora pelo Coronel Biosca na Itália.

A ideia de fornecer exclusivamente comida brasileira, afirma-se nesse relatório, foi abandonada devido a uma comunicação do General Mascarenhas de Morais a Dutra, logo após a chegada da tropa na Itália. Na ocasião pôde-se, então, verificar as reações da tropa à comida de origem estadunidense que the era servida. Segundo Dutra o comandante da FEB teria escrito que:

... o General Mascarenhas de Moraes declarava que não necessitava de remessa de gêneros brasileiros para o Teatro de Operações, mas apenas uma certa quantidade de sal, banha e açúcar para temperar os gêneros nacionais aqui (Itália) existentes, que serão consumidos a título de adaptação, por toda tropa da $1^{\mathrm{a}}$. DIE, pois é preciso ficar bem entendido que os americanos não fornecem gêneros avulsos fora de suas rações típicas. ${ }^{37}$

Menos de cinco meses depois, quando já haviam entrado em ação na Itália todas tropas da $1^{\text {a }}$ Divisão de Infantaria (aliás, a única das três previstas que foi enviada) da FEB seu comandante redigia nova comunicação ao Ministério da Guerra no Rio de Janeiro com teor bem diferente. Em tom de alarme o General Mascarenhas fazia saber à Dutra da enorme demanda de alimentos de origem brasileira, a qual deveria ser enviada de forma contínua.

... a 9 de dezembro recebíamos do comandante da FEB o radiograma no. 2/M: "Solicito máximo empenho... seja 
mantido no Depósito de Intendência no Porto de Livorno o seguinte estoque de víveres brasileiros: 90 toneladas de café moído, 135 toneladas de açúcar, 340 toneladas de feijão, 30 toneladas de arroz, 180 toneladas de farinha de mandioca, 45 toneladas de sal, 34 toneladas de banha, 45 toneladas de mate e 2.225.000 carteiras de cigarros." Isto era a prova de que os nossos combatentes não se haviam adaptado à ração americana, pondo-nos diante do dilema: fornecer apenas gêneros alimentícios brasileiros ou adotar uma etapa mista americano-brasileira. ${ }^{38}$

Parece claro que naquele contexto já se havia abandonado qualquer veleidade de se prover a FEB além-mar exclusivamente com gêneros alimentícios de origem brasileira. Dutra enfatiza em seu relatório as dificuldades de ordem prática ai implícitas, relativas aos fretes marítimos, estocagem e distribuição de suprimentos brasileiros e seu preparo na frente italiana. Ao final de 1944 só estava sendo considerada, portanto, a dieta mista:

Adotamos, então, a segunda solução: aceitarmos a ração americana - substanciosa e prática - para a complementarmos com os gêneros nacionais de que tanta falta sentiram os nossos soldados: feijão, arroz, farinha de mandioca e café. Como os americanos só forneciam a etapa completa, o soldado brasileiro ficou, deste modo, sendo o combatente melhor alimentado da Europa. ${ }^{39}$

Conforme notado ao longo do texto, vários aspectos-chave da história da alimentação servida à FEB seguem desconhecidos ou mal compreendidos pelos historiadores. Somente recentemente o tema vem sendo tomado como objeto de estudo e, portanto, ainda há muito o que descobrir a respeito. Para além de um tópico relevante na área de estudos das relações militares internacionais à época da Segunda Guerra Mundial, o tema também diz respeito à história da alimentação, das transferências e trocas culturais e, lógico, com a "americanização" a que se viu submetido o Exército Brasileiro no decorrer da aliança militar firmada com os EUA. Finalmente, esse objeto de estudo pode ter, por sua vez, alguma relação com a tão propalada predisposição dos pracinhas brasileiros em compartilhar suas rações alimentares com os civis italianos, um fenômeno de recorrência generalizada que marcou de forma duradoura a memória dos habitantes das várias regiões da Itália por onde a FEB esteve durante a guerra. Teria sido mesmo o pracinha brasileiro, conforme afirma Dutra, o mais bem alimentado combatente da Europa? E, nesse caso, esse fato teria algo a ver com a incomparável generosidade demonstrada pelos brasileiros diante das populações civis italianas, famintas e desamparadas? 


\section{NOTAS}

1 Veja-se, por exemplo, MONTEIRO, Érica Gomes Daniel. Quando a Guerra é um Negócio: a cooperação das empresas privadas norte-americanas nos projetos desenvolvidos pelo governo F.D. Roosevelt para a américa latina no contexto da II Guerra Mundial. Tese Doutorado História, UFRJ, 2012. LOCASTRE, Aline V., Projeção do Brasil para o Pós-guerra: A 'Boa Vizinhança' estadunidense no Brasil segundo a revista 'Em Guarda' (1941-1945). Dissertação História, UEL, 2012. STUMPF, Derli Junior. Encontrando um Novo Mefisto: a americanização do Exército e a Revista Defesa Nacional, 1942-1950. Mestrado, História, UPF, 2010 RODRIGUES, Fernando da Silva. As Relações Militares Brasileiras durante a Segunda Guerra Mundial. Revista Brasileira de História Militar. a. II, n. 6, dez. 2011. p. 17-18, A Formação Profissional do Oficial do Exército Brasileiro na Primeira Metade do Século XX: a Influência dos Jovens Turcos, da Missão Indígena e da Missão Militar Francesa. R. Mest. Hist., Vassouras, v. 13, n. 1, p. 31-52, jan./jun. 2011, Da Chegada da Missão Militar Americana no Brasil em 1936 à dominação total da influência doutrinária do Exército do Tio Sam no Exército do Zé Carioca. Cadernos da FaEL. , v.1, p. 1 - 15, 2008. CUNHA, Ioneida Cavalcanti da. Ideologia e Propaganda na Cooperação Estados Unidos Brasil na Segunda Guerra Mundial: o caso das empresas aéreas. Mestrado Relações Internacionais, UNB, 2008. LATFALLA, Giovanni. O Estado-Maior do Exército e as Negociações Militares Brasil-Estados Unidos Entre os Anos de 1938 e 1942. In: Caminhos da História, Vassouras, v. 6, n. 2, p. 61-78, jul./dez. 2010. SVARTMAN, Eduardo Munhoz. Oficiais do Exército Brasileiro nos EUA: experiência, memória e incorporação seletiva de idéias nas décadas de 1930 e 40. In: ANPUH - XXV Simpósio Nacional de História - Fortaleza, 2009, O Pragmatismo Brasileiro na Cooperação Militar com os Estados Unidos, nas décadas de 1930 e 40 Estudos Ibero-Americanos, PUCRS, v. XXXIV, n. 1, p. 76-91, jun. 2008. Da Segunda Guerra Mundial à Guerra Fria: Conexões entre os exércitos do Brasil e dos Estados Unidos. Latin American Research Review, v. 49, n. 1. 2014, Fascismo e Politica Externa no Prata: elementos para uma comparação de idéias e atores na Argentina e no Brasil (1930-1945), In: Segundas Jornadas de História Regional Comparada, 2005, Porto Alegre.. FREIRE JUNIOR, Olival; SILVA, Indianara Silva. Diplomacia e Ciência no Contexto da Segunda Guerra Mundial: a viagem de Arthur Compton ao Brasil em 1941. Revista Brasileira de História. São Paulo, v. 34, n. 67, p. 181-201, 2014. MORAES, Isaias Albertin de. Política e Cinema na Era da Boa Vizinhança (1933-45) Disponivel em: <http://periodicos.franca. unesp.br/index.php/historiaecultura/article/view/1487. Acesso em: 21 fev. 2015. HENRIQUE, Heitor Esperança. Força Aérea Brasileira na Segunda Guerra Mundial: a participação de um país periférico numa guerra moderna. Dissertação História, UEM, 2014.

2 MERON, Luciano. Saco vazio não para em pé: a alimentação e os hábitos alimentares na FEB (1944-1945). Anais do I Seminário Alimentação e Cultura na Bahia. Centro de Estudos do Reconcavo, UEFS, 2014. Pp. 1-10

3 MOURA, Gerson. Autonomia na dependência: a política externa brasileira de 1935 a 1942. Rio de Janeiro: Nova Fronteira, 1980. Do mesmo autor, Relações Exteriores do Brasil, 193950: mudanças na natureza das relações Brasil-Estados Unidos durante e após a Segunda Guerra Mundial. Brasília: Fundação Alexandre de Gusmão, 2012. SEITENFUS, Ricardo. O Brasil vai à Guerra: o processo do envolvimento brasileiro na Segunda Guerra Mundial. São Paulo: Manole, 2003. MCCANN JR, Frank D. Aliança Brasil Estados Unidos 1937/45. Rio de Janeiro: Bibliex, 1995. O texto originalmente é de 1973. CONN, Stetson; FAIRCHILD, Byron. A Estrutura de Defesa do Hemisfério Ocidental.Rio de Janeiro, Bibliex, 2000. Originalmente publicado em 1960 e com uma primeira edição brasileira em 1989. ALVES, Vágner Camilo. Da Itália à Coréia: decisões sobre ir ou não à guerra. Rio de Janeiro/Belo Horizonte: Editora UFMG/ IUPERJ, 2007 e também O Brasil e a Segunda Guerra Mundial: autonomia na dependência? 
In: OLIVEIRA, Dennison de (Org.). A Força Expedicionária Brasileira e a Segunda Guerra Mundial: estudos e pesquisas. 1. ed. Rio de Janeiro: CEPHiMex, 2012. p. 100-105.

4 OLIVEIRA, Dennison de. Aliança Brasil-EUA: Nova História do Brasil na Segunda Guerra Mundial. Curitiba: Juruá, 2015.

5 idem

6 idem

7 idem

8 LEITÃO DE CARVALHO, A serviço do Brasil na Segunda Guerra Mundial. Rio de Janeiro: Bibliex, 1952. p. 301.

9 Idem, p. 214

10 idem

11 Idem, p. 253

12 Idem, p. 355

13 idem

14 Idem, p. 393

15 CARVALHO, Estevão Leitão de. Documentos citados no Relatório do Chefe da Delegação Brasileira da Comissão Mista Brasil-EUA. Curitiba, Legião Paranaense do Expedicionário, sem data. p. 58 Imagens 5692 e 5693 disponíveis em https://drive.google.com/drive/folders/0B4 vcLWzR_ouTGhOazJKM3VHYmc Acessadas em 21/02/2016

16 LEITÃO DE CARVALHO, 1952. P. 404

17 Idem, p. 408.

18 CARVALHO, Estevão Leitão de. Relatório Geral do Chefe da Delegação Brasileira a Comissão Mista de Defesa Brasil-Estados Unidos. Washington, 1945. p. 42

19 PIASON, José Alfio. Alguns erros fundamentais observados na FEB. In: ARRUDA, Demócrito Cavalcanti de (org.) Depoimentos de Oficiais da Reserva sobre a FEB. São Paulo: Instituto Progresso Editorial S.A. 1950. P. 82

20 CALDAS, Mirandolino. O posto avançado de neuro-psiquiatria da FEB, $2^{\mathrm{a}}$. edição, Rio de Janeiro, 1950, pp. 14-16

21 Idem p. 16

22 Idem p. 21

23 PIASON, op. cit. p. 82

24 Agradeço ao pesquisador Cesar Campiani Maximiano pelas informações

25 MENDES, Ubirajara Dolácio. Soldado com fome não briga. In: ARRUDA (1950) p. 241

26 Idem

27 Idem, p. 247

28 Idem

29 BIOSCA, Fernando L. A intendência no Teatro de Operações da Itália. Rio de Janeiro: Bibliex, 1950, pp. 196-197 
30 Idem p. 198

31 Idem p. 199

32 Idem p. 205

33 Idem p. 201- 203

34 Idem p. 207

35 Imagem 13g disponível em https://drive.google.com/drive/folders/0B4_vcLWzR oufkN5ZXFHMUYwaUNiMmhwYlBHYm04X3RTaUZLcEM5N1hfaGMtbk5DZIVqTGs Acessada em 21/02/2016

365692

37 BRASIL 1945 imagem 444 e 445 disponíveis em https://drive.google.com/drive/ folders/0B4_vcLWzR_ouUU9SYnRXTUppYlE acessadas em 21/02/2016

38 Idem

39 Idem

Artigo recebido em janeiro de 2016. Aceito em abril de 2016. 